\title{
Differences in handgrip strength protocols to identify sarcopenia and frailty - a systematic review
}

\author{
A. R. Sousa-Santos ${ }^{*}$ and T. F. Amaral
}

\begin{abstract}
Background: Hand grip strength (HGS) is used for the diagnosis of sarcopenia and frailty. Several factors have been shown to influence HGS values during measurement. Therefore, variations in the protocols used to assess HGS, as part of the diagnosis of sarcopenia and frailty, may lead to the identification of different individuals with low HGS, introducing bias. The aim of this systematic review is to gather all the relevant studies that measured HGS to diagnose sarcopenia and frailty and to identify the differences between the protocols used.

Methods: A systematic review was carried out following the recommendations of The Preferred Reporting Items for Systematic Reviews and Meta-Analyses (PRISMA) Statement. PubMed and Web of Science were systematically searched, until August 16, 2016. The evidence regarding HGS measurement protocols used to diagnose sarcopenia and frailty was summarised and the most recent protocols regarding the procedure were compared.

Results: From the described search 4393 articles were identified. Seventy-two studies were included in this systematic review, in which 37 referred to sarcopenia articles, 33 to frailty and two evaluated both conditions. Most studies presented limited information regarding the protocols used.

Conclusions: The majority of the studies included did not describe a complete procedure of HGS measurement. The high heterogeneity between the protocols used, in sarcopenia and frailty studies, create an enormous difficulty in drawing comparative conclusions among them.
\end{abstract}

Keywords: Sarcopenia, Frailty, Handgrip strength, Older adults

\section{Background}

Ageing is accompanied by numerous underlying physiological changes and increasing risk of certain health conditions, such as chronic diseases. These changes that constitute and influence ageing are complex [1]. Sarcopenia and frailty are two geriatric syndromes that are frequently confounded [2].

Sarcopenia was initially proposed by Irwin Rosenberg, in 1989 , to define the age-related decrease of muscle mass. It derives from the Greek words 'sarx', that means flesh, and 'penia', that means loss [3]. In 2009, the International Working Group on Sarcopenia (IWGS) provided a consensus definition describing sarcopenia as the age-associated loss of skeletal muscle mass and

\footnotetext{
* Correspondence: anaritadesousasantos@gmail.com

Faculdade de Ciências da Nutrição e Alimentação, Universidade do Porto, Rua Dr. Roberto Frias, 4200-465 Porto, Portugal
}

function. It was proposed that older patients who presented decline in physical function, strength or overall health should be considered for sarcopenia diagnosis [4]. In 2010, the European Working Group on Sarcopenia in Older People (EWGSOP) released a clinic definition and a consensus diagnostic criteria for age-related sarcopenia. They presented sarcopenia as a syndrome characterised by progressive and generalised loss of skeletal muscle mass and strength with a risk of adverse outcomes such as physical disability, poor quality of life, and death. The diagnosis should consider the presence of low muscle mass and low muscle function (strength or performance) to define conceptual stages as 'presarcopenia,' 'sarcopenia' and 'severe sarcopenia' [2].

Frailty is a clinically recognisable state of increased vulnerability resulting from age-associated decline in reserve and function across multiple physiologic systems 
[5], which is associated with adverse outcomes, such as falls, functional decline, hospitalisations and mortality [6-9]. Even though, there is no single generally accepted clinical definition of frailty, in the Cardiovascular Health Study (CHS) it was defined as a clinical syndrome in which three or more of the following characteristics were present: unintended weight loss, exhaustion, weakness, slow gait speed and low physical activity [10]. Fried's frailty scale has been the most extensively tested for its validity and is the most widely used instrument in frailty research [11].

Hand grip strength (HGS) is used to diagnose both sarcopenia and frailty $[2,4,10]$. It can be quantified by measuring the amount of static force that the hand can squeeze around a dynamometer [12] and it is an indicator of overall muscle strength [13]. Age and gender are described as the strongest factors influencing HGS in healthy subjects, HGS declines with increasing age [14] and presents lower values for women $[15,16]$. It has good intra- and inter-tester reliability and can be recommended the use in clinical practice $[17,18]$. HGS can independently identify changes in nutritional status [19]; it responds earlier than anthropometrical measurements to nutritional deprivation and has shown to be significantly associated with sarcopenia [2] and frailty [10].

While HGS is considered a reliable measure to assess muscle strength, several factors have been shown to influence HGS values during measurement. It was reported that a different posture [20], different positions of the elbow [20] and wrist [21], the hand used to test [22] and the setting of the dynamometer [23] may affect the values of strength. It is even reinforced that certain positions can optimise the measurement and produce a maximal HGS. Therefore, variations in the protocols used to assess HGS, as part of the diagnosis of sarcopenia and frailty, may lead to the identification of different individuals with low HGS, introducing bias. This can occur even when the same cut-off points are adopted, which consequently can lead to differences in the number of individuals identified with sarcopenia and frailty.The American Society of Hand Therapists (ASHT) recommended, in 1981, that HGS should be measured with the individuals seated with their shoulders adducted, their elbows flexed $90^{\circ}$ and their forearms in neutral position using the Jamar dynamometer [24]. This protocol has been updated with more details of the procedure in 1992 [25], and later in 2015 [26]. In 2011, a new protocol was proposed, the Southampton protocol [27], representing another step towards an improvement of the description of HGS measurement. Nevertheless, there is still a lack of consistency in the studies' protocols to evaluate HGS used over time.
This systematic review resulted from the need to evaluate the differences between the protocols used for the HGS measurement to diagnose sarcopenia and frailty in older adults. For this reason, this revision represents a step forward towards the standardisation of the procedure. Therefore, the aim of this article is to gather all the relevant studies that measure HGS and to identify the differences between the protocols used. To this end, the proposed systematic review will answer the following questions:

1. Which dynamometer was used for measuring HGS?

2. Which hand was used?

3. What was the individual's posture?

4. What was the arm position?

5. Which handle position was used?

6. How long did the HGS measurement take?

7. How long were the intervals between the measurements?

\section{Methods}

A systematic review was carried out following the recommendations for reporting systematic reviews and meta-analyses of the Preferred Reporting Items for Systematic Reviews and Meta-Analyses (The PRISMA Statement) [28]. PubMed and Web of Science were systematically searched until August 16, 2016, with no restriction on the year of publication. The search was limited to English, Portuguese, Spanish and French publications and to human subjects. The reference lists within the articles were scanned for any additional references missing from the databases' search. The following search terms were used: [1] ((hand OR handgrip OR grip OR grasp) AND (force OR strength)) AND (sarcopenia OR frail elderly OR frail OR frailty). Subsequently, search results were inserted in EndNote X7 and duplicates were excluded. All the titles and abstracts were screened based on the eligibility criteria and classified as "relevant" or "not relevant". Full texts of eligible articles were assessed and read. Those that met all criteria were included.

\section{Eligibility criteria}

Studies were included if [1] participants were aged 65 years or older within well-defined samples, with a clear description of the inclusion and exclusion criteria; [2] sarcopenia and frailty were considered as outcomes, in which HGS was used to identify this condition; [3] a description of the protocol used to measure handgrip strength was provided; [4] the outcome measures described are: type of dynamometer for the assessment of HGS, individual's position (including shoulder, elbow, arm and handle position and posture), hand dominance, 
number of repetitions, acquisition and rest time, encouragement and handgrip strength values.

Randomised control trials, cohort studies, case control studies and cross-sectional studies were included, and meta-analyses or review articles, case reports, case series, meetings' proceedings, conference summaries and duplicate records were excluded. Articles were not included if information about either the posture of the individual, or concerning the arm position (shoulder, elbow or wrist) was absent. When the complete procedure was not described but a reference was made to another article, we searched for the missing parts of the procedure. If the article did not add more details regarding the procedure, it was still excluded. In case of disagreement about the inclusion of a study, the reviewers discussed their opinions to reach consensus. The studies were divided into two subgroups: [1] articles about sarcopenia and [2] articles about frailty. Final studies selected for inclusion in each category were independently compiled in data tables. Articles which presented the same data as an earlier study were still excluded.

\section{Results}

From the described search 4393 articles were identified. After removing duplicates, a total of 2753 articles remained. From these, after screening for title and abstract 2166 articles were excluded. Five hundred and eighty-seven full-text articles were assessed for eligibility and 515 references were excluded. Seventy-two studies were found eligible and, therefore, included in this systematic review. Figure 1 presents a flow diagram of the literature search and of the selection process.

The studies comprised in this systematic review were published between 2003 and 2016. Fifty-two were crosssectional studies, 17 were cohorts, and three were clinical trials. The sample size ranged between 24 and 11,844 individuals.

From the articles included, 37 studies referred to sarcopenia, 33 to frailty and two evaluated both conditions. The EWGSOP and the CHS definitions were used in the majority of studies to diagnose sarcopenia and frailty.

\section{Description of HGS measurement}

Most studies presented limited information regarding the protocols used. As shown in both Tables 1 and 2, all 72 studies described the dynamometer used, but only five specified if it was calibrated for the study. Although, there was a wide range of equipment used, the Jamar dynamometer was the most mentioned $(n=35)$, followed by the Smedley dynamometer $(n=10)$. Sixty-

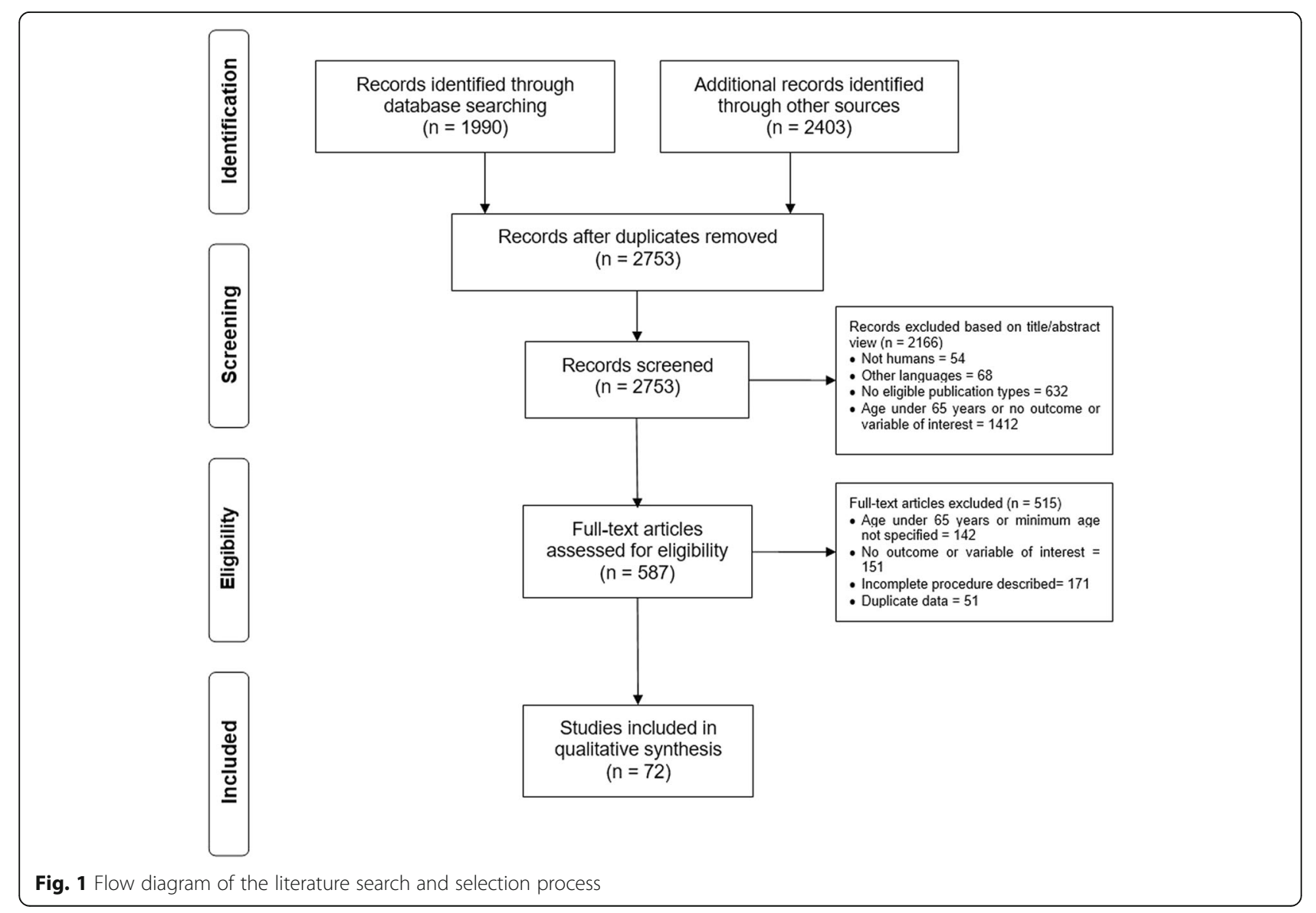




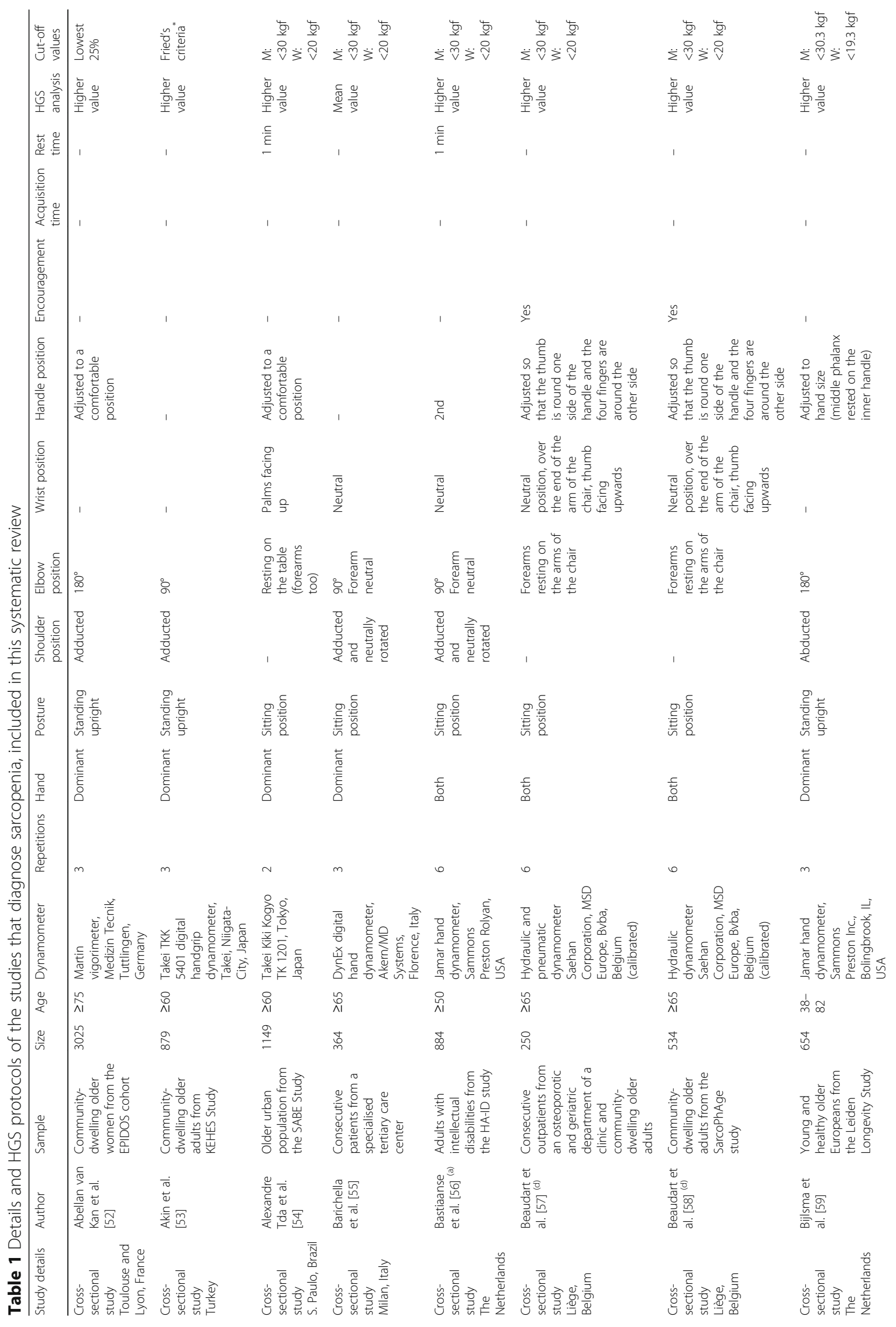




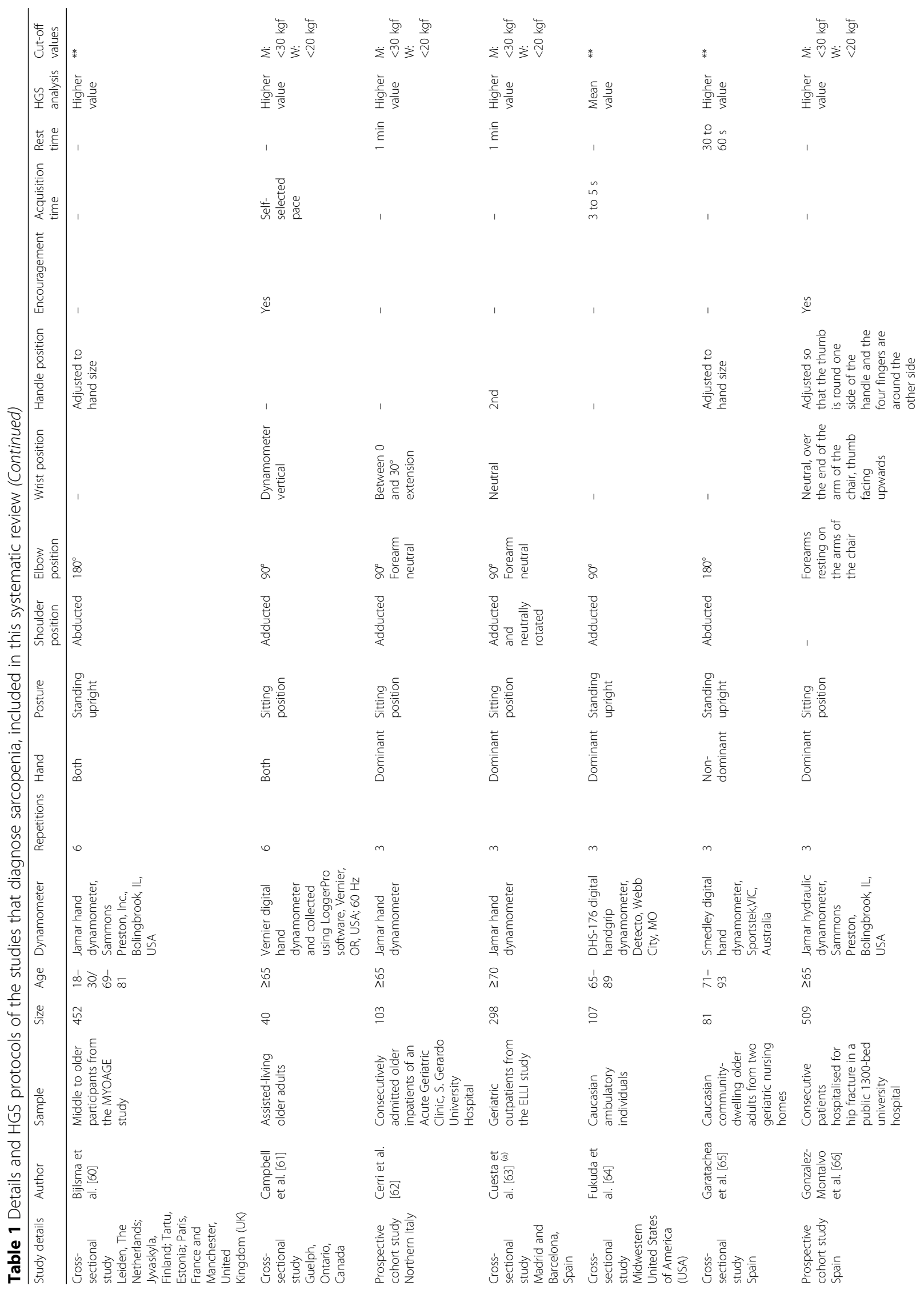




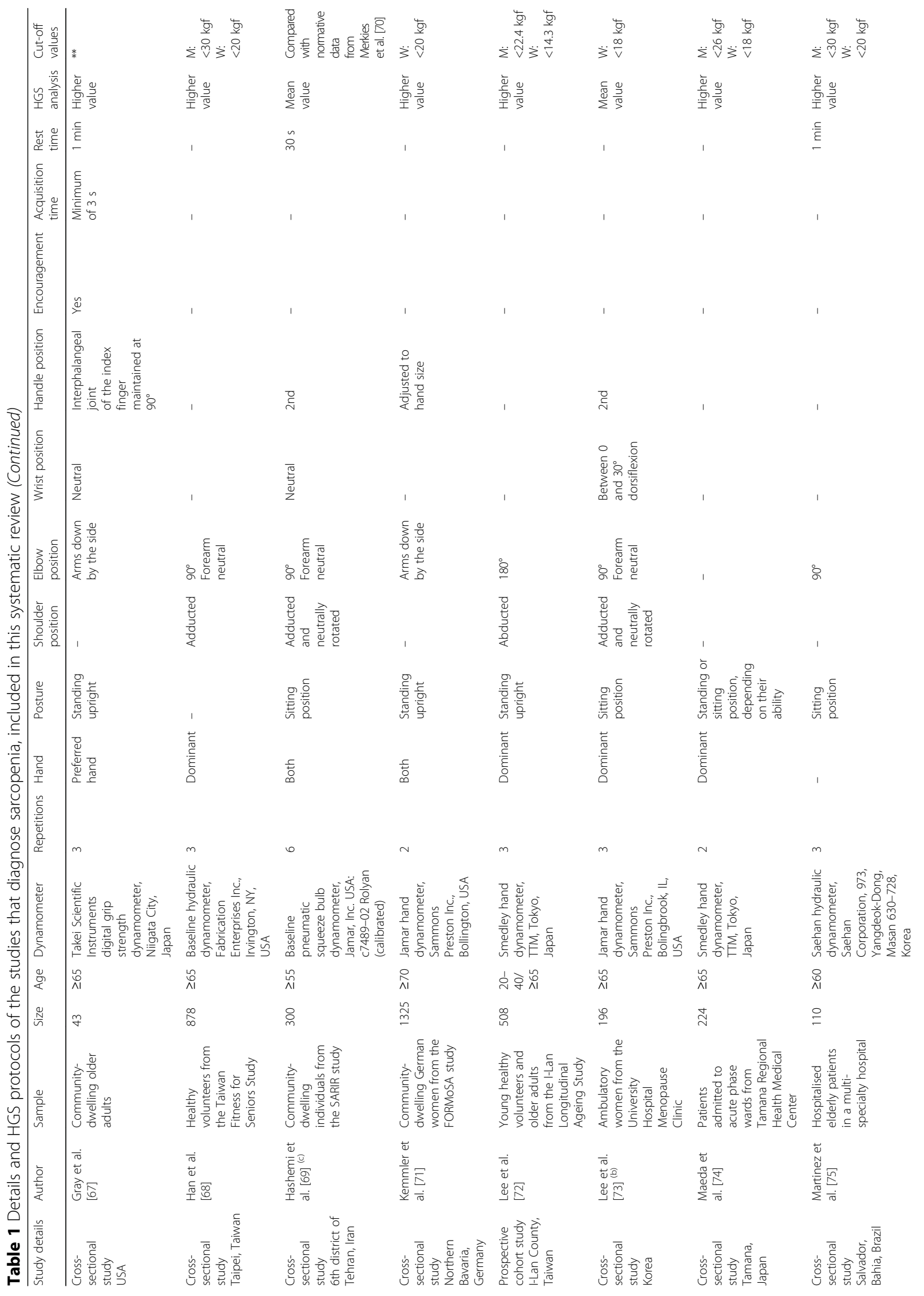




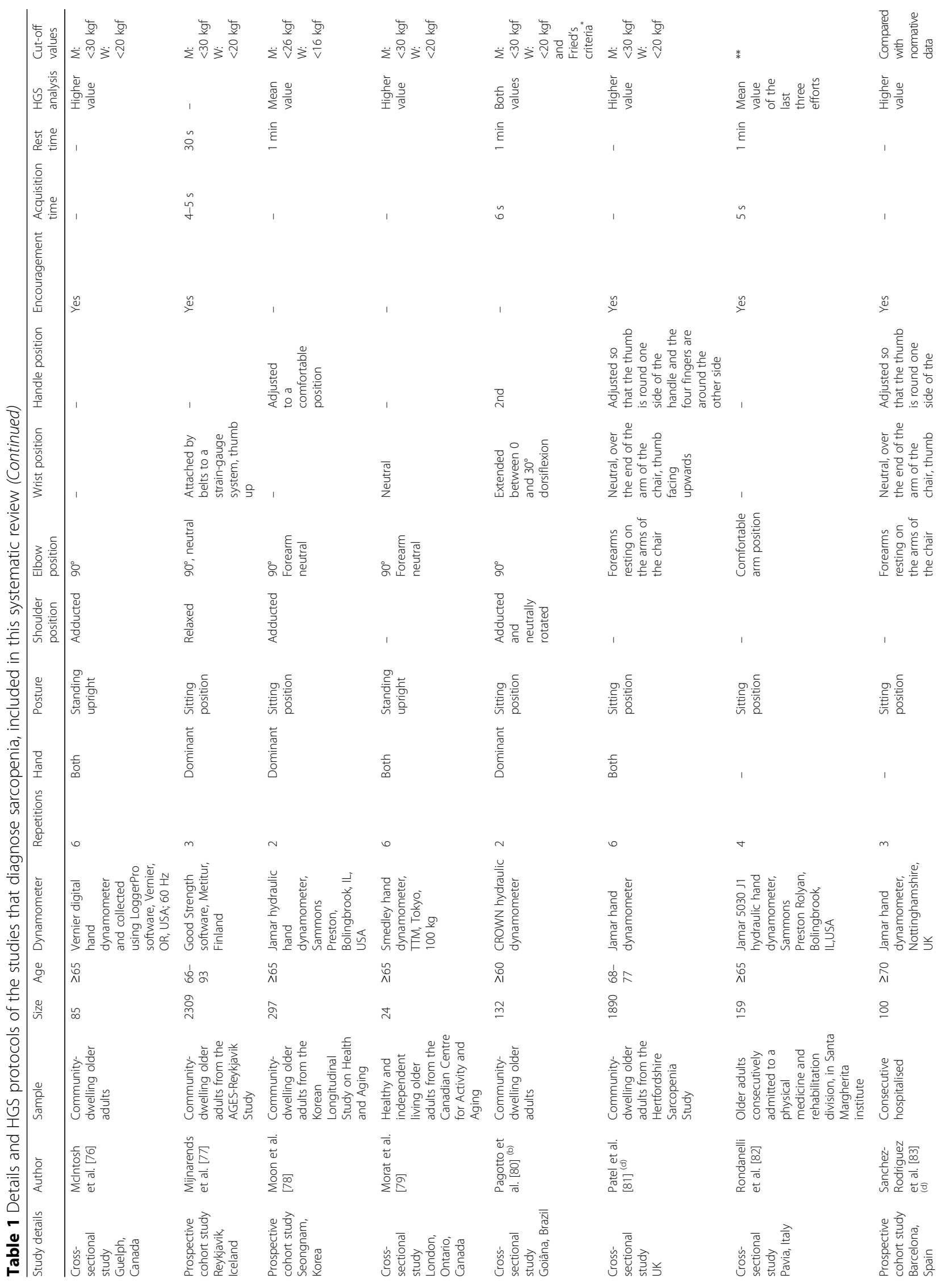




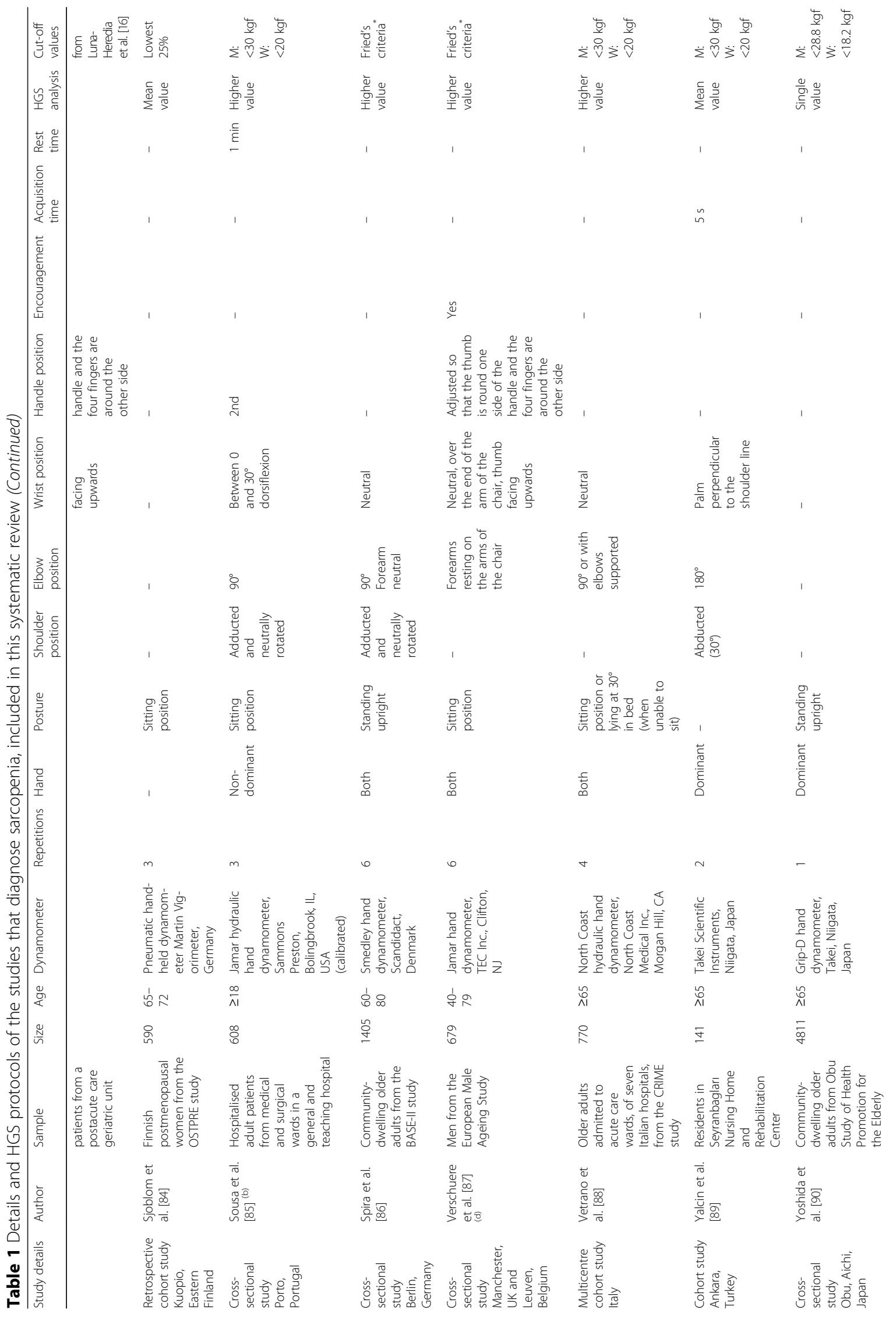




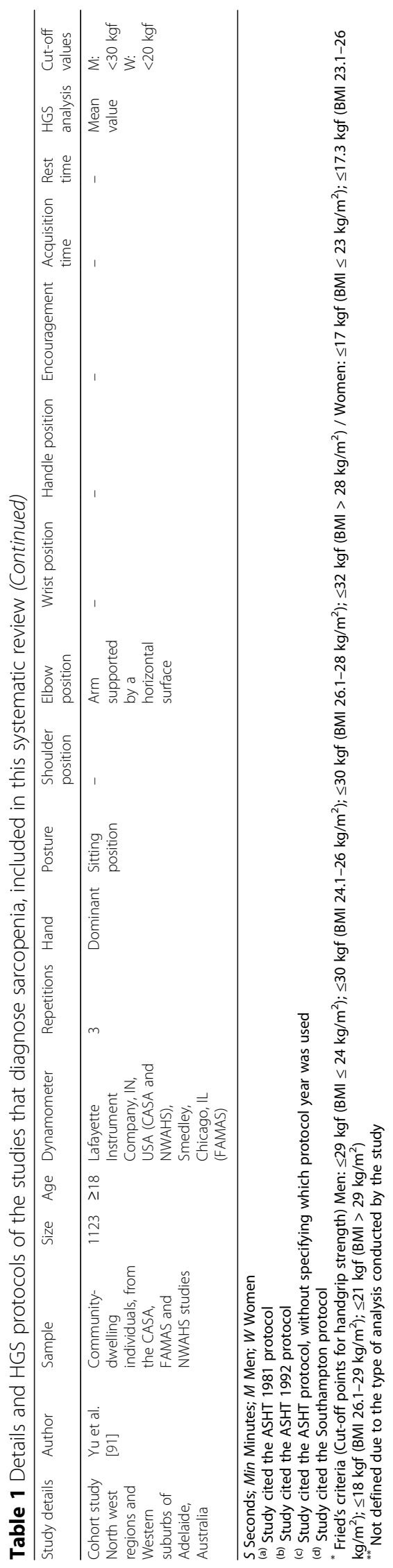




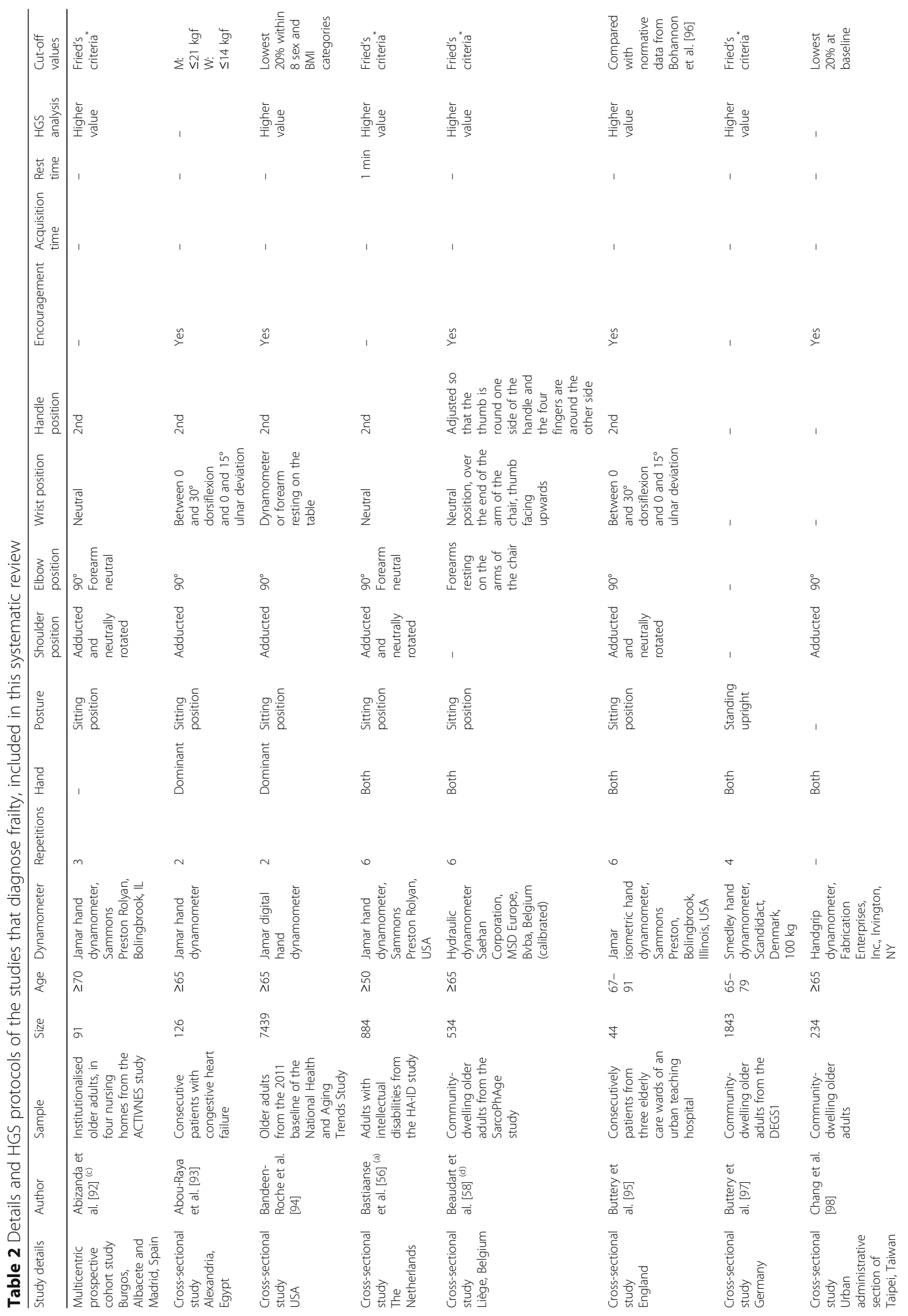




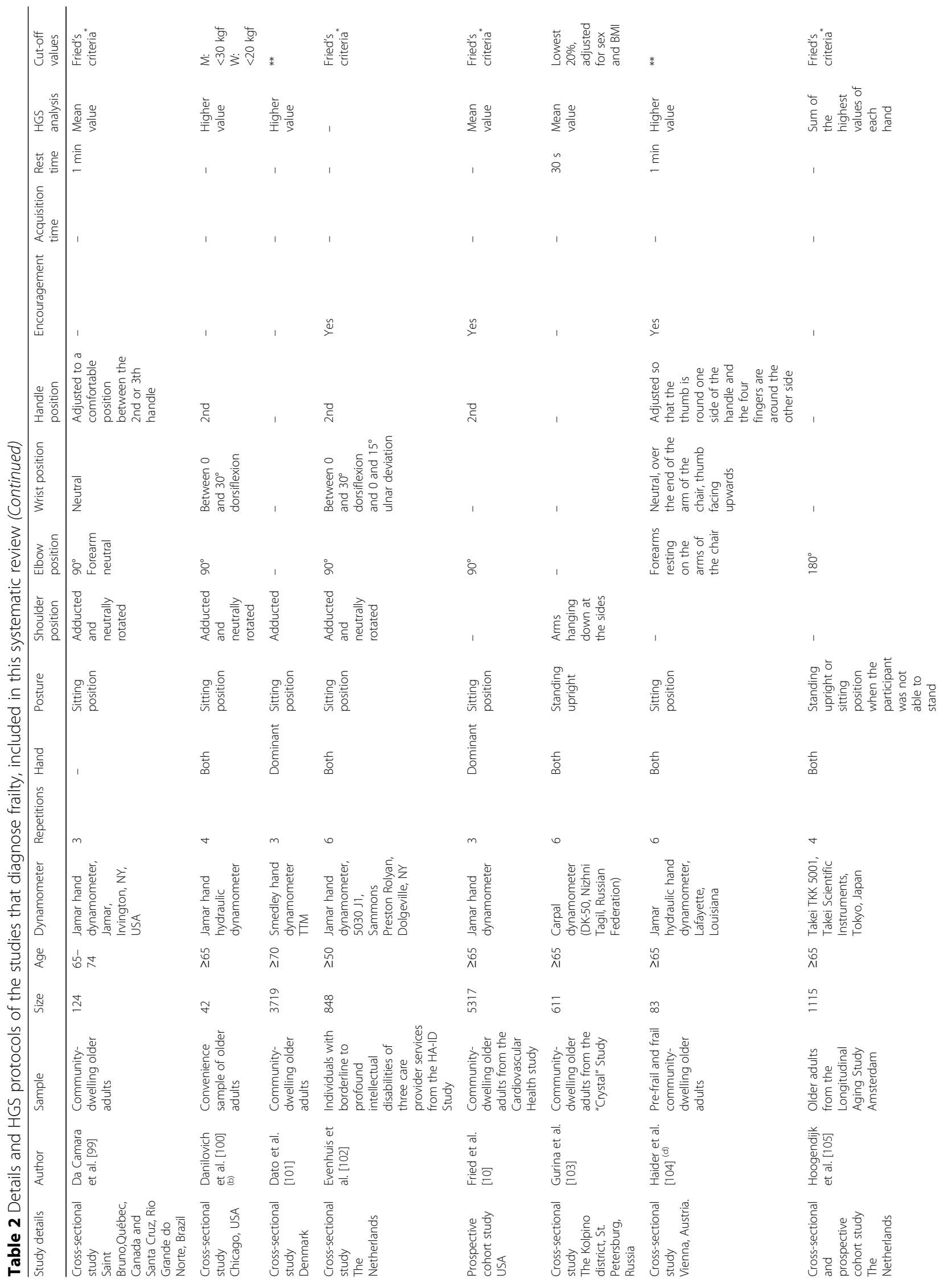




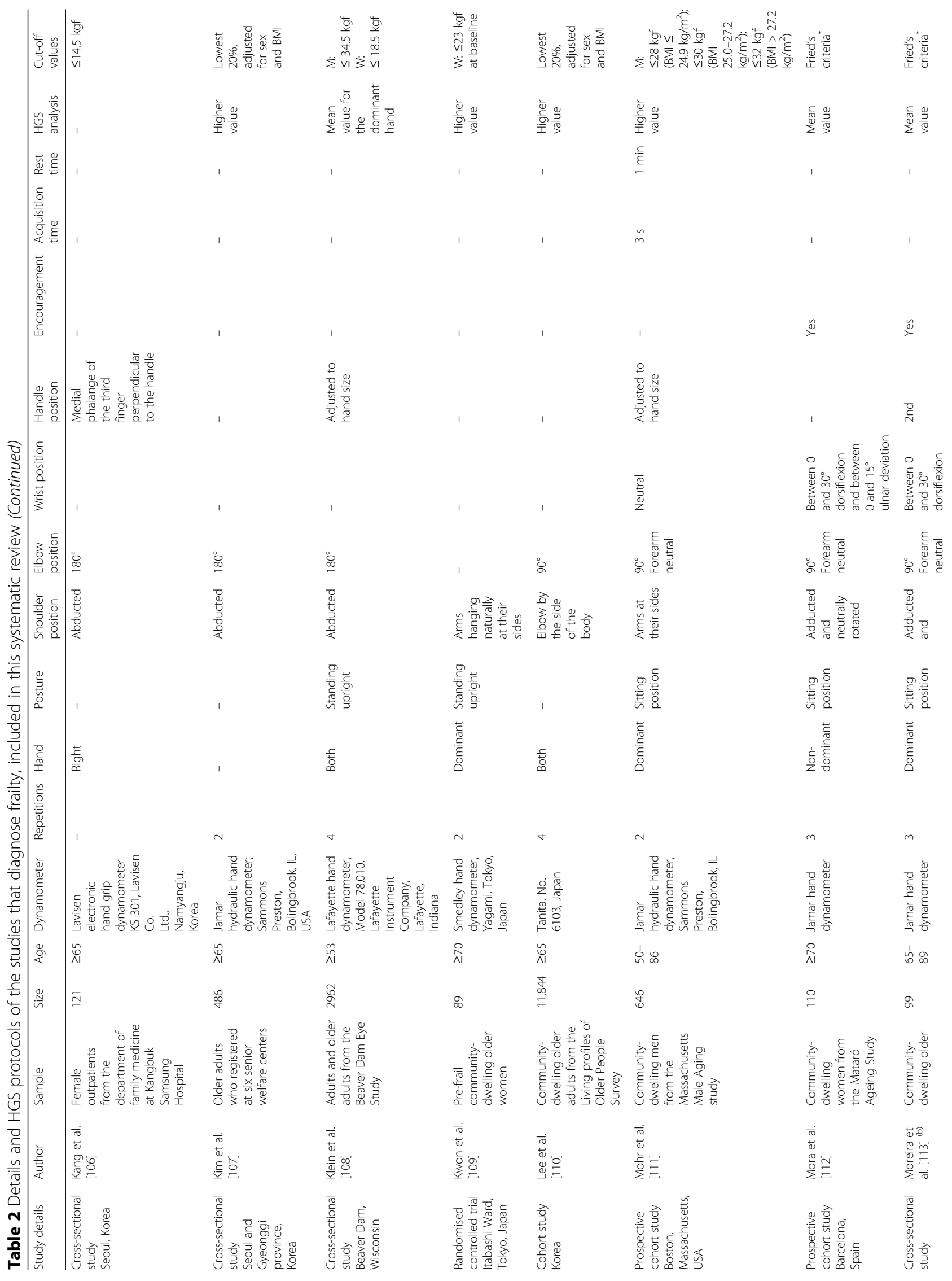




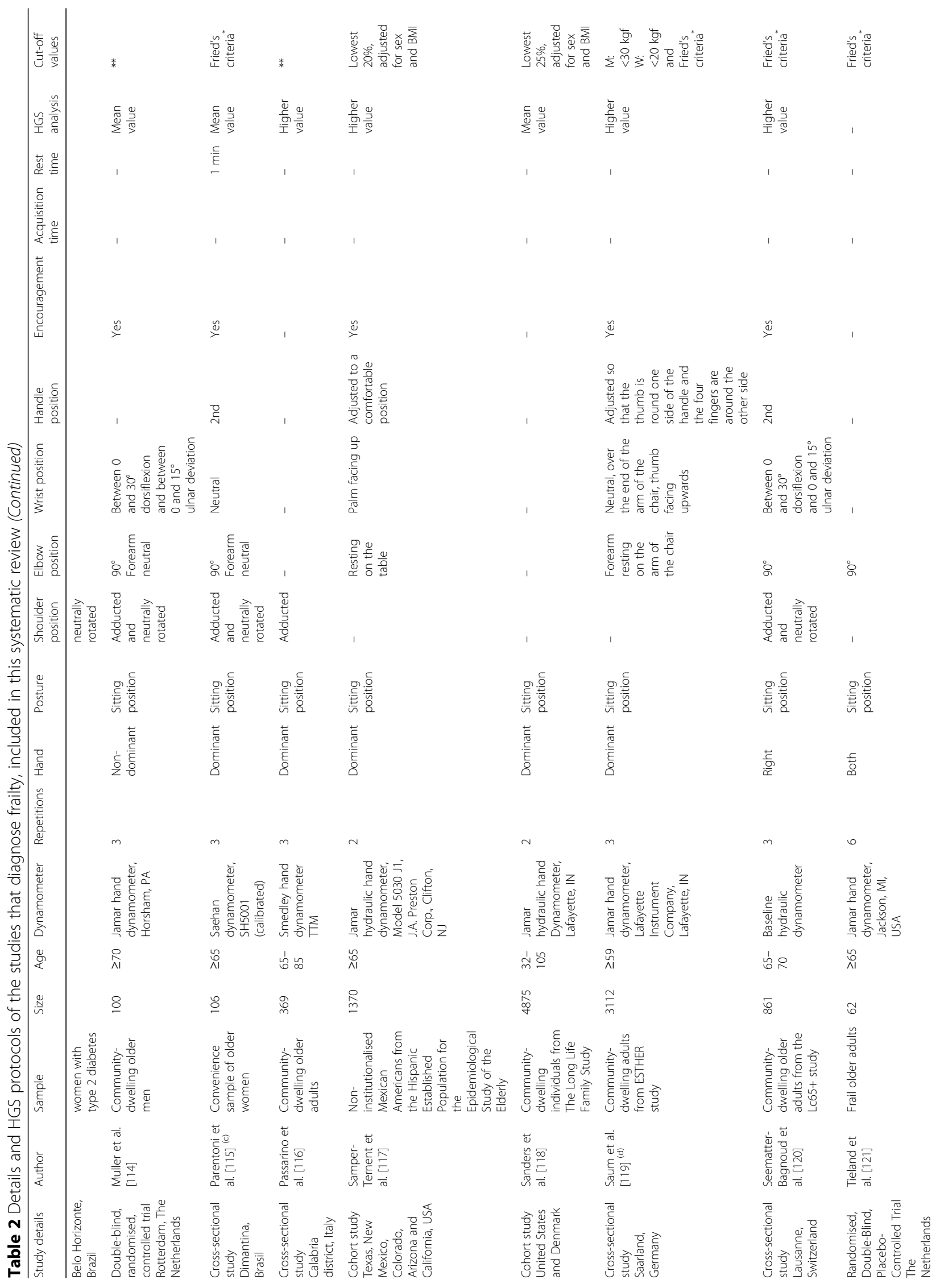




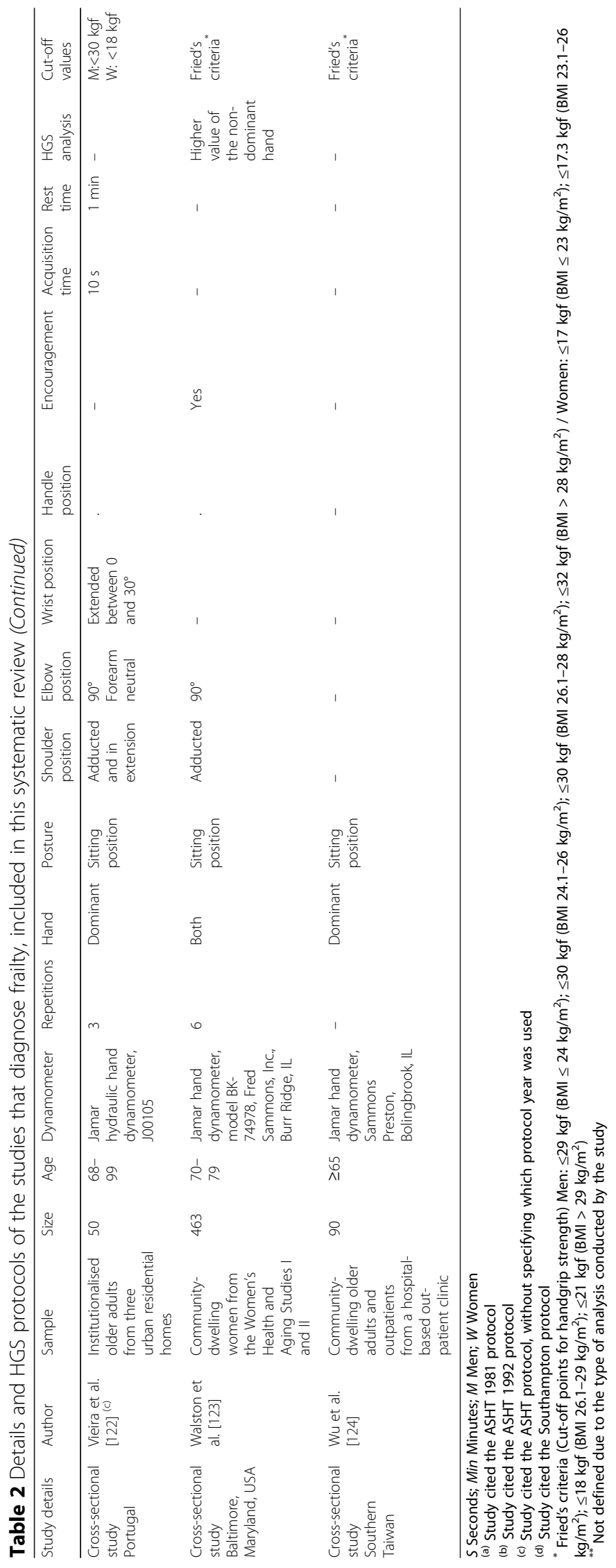


six studies described the posture of the individual, in which the majority was measured in a sitting position $(n=47)$, and 19 were in a standing position. Three studies mentioned variations regarding the posture, depending on the ability of the individuals.

Most studies chose to measure HGS only in the dominant hand $(n=33)$, in four studies measurement was obtained from the non-dominant, and in 25 in both dominant and non-dominant. In one study HGS was measured using the preferred hand while the right hand was used in two other studies. In seven articles information about the chosen limb was absent. The position of the shoulder and the elbow was indicated in 46 and 62 studies, respectively, and the wrist position was described in 39 studies. The dynamometer's handle was referred in 37 articles, while the second handle position was mentioned in 16 articles. Encouragement during the procedure was reported in 26 studies, only nine studies indicated the data acquisition time and, 19 studies specified the rest time. Most studies $(n=42)$ used the higher HGS value for the analysis. The ASHT protocol was mentioned in 11 studies, of which the 1981 protocol was referred twice and the 1992 protocol was cited in five studies. The others did not specify the ASHT protocol used. The Southampton protocol was alluded to in eight studies.

\section{Discussion}

The aim of this systematic review is to identify the HGS protocols used to diagnose sarcopenia and frailty. The heterogeneity in HGS protocols, the wide variability in the criteria used to identify either sarcopenia and frailty and the different inclusion and exclusion criteria in the evaluated studies is an issue in this research field. Indeed, these differences hinder comparison between the studies and hamper progress of the study of these conditions.

We observed that most studies which diagnose these conditions did not mention the protocol used in the measurement of HGS, or did not include a full description of it. Although the ASHT and Roberts et al. proposed standardised protocols, the results of the present review showed high heterogeneity of the chosen procedure. Studies concerning sarcopenia and frailty did not differ in standardised protocols used. Plus, the complete description of the procedure is lacking in most studies. In trying to overcome this problem, some authors raise an additional difficulty when they cite the previous publication of their study protocol.

The parameters regarding the HGS procedure that were presented in the Tables 1 and 2 and its influence in HGS values were evaluated in several studies. As shown below, in spite of some results being similar between the studies, others present contradictory results.

\section{Dynamometer}

The ASHT recommends a calibrated Jamar dynamometer in the second handle position for the measurement of HGS [24-26]. While, the Southampton protocol suggested the handle should be adjusted so that the thumb is round one side of the handle and the four fingers are around the other side and the instrument should feel comfortable in the hand [27].

The Jamar hydraulic dynamometer presents higher intra and inter-individual reliability [17]. Despite this being referred to as the most widely used and tested dynamometer [27], this review shows a great variability in the dynamometers used, regardless of Jamar's predominance. Present results exhibit a great number of studies which failed to describe if the instruments were properly calibrated for the measurements. A correctly calibrated dynamometer is highly reliable. Nevertheless, it should be recalibrated regularly [29].

Other dynamometers, such as Smedley dynamometer (mechanical) and Martin vigorimeter (pneumatic), measure HGS by a different mechanism [30]. Concerning the Smedley dynamometer, it has shown excellent results regarding its laboratory tested accuracy but, when applied among older adults, it did not produce comparable results to the Jamar hydraulic [31]. Low agreement between Jamar dynamometer and Takei dynamometer was observed [32]. Otherwise, the results of the comparison between the Jamar dynamometer and the Martin vigorimeter in a healthy elderly population, indicate a very high correlation between the two HGS data values [33]. When the hydraulic dynamometers, Baseline and Saehan, were tested they shown to be valid, reliable and comparable to the Jamar dynamometer $[34,35]$.

\section{Hand}

A summary of the studies comparing HGS in dominant and non-dominant limbs, revealed that it is reasonable to expect greater grip strength in the dominant upper extremity in right-handed individuals [36]. Yet, it is important to consider that the difference between sides varies widely among studied samples and in a significant proportion of individuals the opposite is observed [37, 38].

\section{Posture and arm position (shoulder, elbow and wrist)}

Most studies revised here, a standing or sitting position was selected. In some cases, the position was adapted to the individual's physical function. The influence of the standing versus sitting posture in HGS values was evaluated and no significant differences were found by several studies [39-41]. When comparing standing versus sitting position, Balogun et al. observed significant differences only between sitting with elbow at 90 degrees and standing with elbow at full extension [20]. These results were 
in agreement with one study that showed that grip strength is significantly greater when measured with the elbow in the fully extended position [42]. Additionally, even though the posture alone did not significantly influence HGS values, combined with the elbow position it could indicate the presence of an interaction between the elbow position at 180 degrees and a standing position. On the other hand, other results showed a stronger grip strength measurement in the 90 degrees elbow flexed position than in the fully extended position $[41,43]$.

$\mathrm{Su}$ et al. also evaluated different shoulder and elbow positions. They observed that when the shoulder was positioned at 180 degrees of flexion with elbow in full extension the highest mean grip strength measurement was recorded; whereas the position of 90 degrees elbow flexion with shoulder in zero degrees of flexion produced the lowest grip strength score [44]. While, De et al. did not find significant differences when shoulder joints varied between 90 and 180 degrees [41].

Regarding the wrist position, one study suggested that a minimum of 25 degrees of wrist extension was required for optimum grip strength [21]. Later, it was shown that HGS measured with wrist in a neutral position was significantly higher than that in the wrist ulnar deviation [41] and, in another study that the mean grip strength scores were higher for all the tested six positions when wrist was positioned in neutral than in extension position [45].

\section{Handle position}

Some researchers opted for HGS measurement in a standard handle position. However, in others, researchers adapted the handle to hand size or to a comfortable position for the individual. It was suggested that hand size and optimal grip span only correlated in women [46]. Other studies results have shown that the second handle position was the best position for the majority of the participants. Therefore, the authors suggested the use of a standard handle position (second setting) over multiple different positions [23, 47]. This would provide accurate results and increase the comparability of the results [47].

\section{Repetitions}

Mathiowetz et al. suggested that the mean of three trials is a more accurate measure than one trial or even the highest score of three trials [48], while the latter was the most widely adopted by the studies included in this systematic review. In contrast, it was suggested that muscle fatigability might occur with each attempt and one trial is sufficient for the measurement of grip strength [49]. In another study, it was observed that the mean values of grip strength generated for each method of grip strength testing (one trial, the mean of three trials, and the best of three trials) produced comparable results [50].

\section{Encouragement}

To our knowledge, only one research described the effects of the encouragement during HGS measurement. It showed that instruction, verbal encouragement, and visual feedback had critical effects on the handgrip strength and, therefore it should be mentioned in the articles [51]. More than half of the articles included here did not provide a full description of if and how the encouragement was made during the trials.

\section{Analysis}

As described above, most studies used the higher value for the HGS analysis, however other forms of HGS values chosen by the authors, such as the mean or the sum of the values obtained during the measurements was also observed. Hence, the diagnosis of sarcopenia and frailty between the studies is even less comparable.

\section{Comparison of the protocols}

Although the most recent ASHT protocol presents more details regarding the HGS measurement, this protocol has not been adopted by any of the studies included in this revision. Almost every aspect was described in the protocol, making the variations between the studies almost impossible, but also increasing the complexity of the measurement, and therefore the duration of the procedure. Despite the fact that the Southampton protocol referred to all the aforementioned aspects in Table 3, it did not describe in detail the joints position, which could lead to variations in HGS values between the studies.

Due to the great variability in the studies concerning sarcopenia and frailty, namely in the inclusion and exclusion criteria, and in the definition and procedures used to identify these conditions, it is difficult to evaluate the impact of each parameter of the procedure in HGS values. Therefore, to diminish the heterogeneity observed in the studies, the most recent ASHT protocol should be adopted. Variations in the procedure are strongly discouraged, however when it is impossible to fully implement this protocol, namely due to the individuals' health conditions, any variation should be reported.

\section{Main topics}

The mixed results above discussed reinforce the need to standardise HGS measurement. The difference between the protocols can influence the HGS results and, consequently, affect the comparability between the studies. A common approach would be not only important for research purposes but also for clinical practice. For both 
Table 3 Recent HGS protocols proposed

\begin{tabular}{|c|c|c|}
\hline & ASHT protocol - 2015 [26] & Southampton protocol - 2011 [27] \\
\hline Posture & $\begin{array}{l}\text { Subject seated in a chair without arm rests, with feet } \\
\text { fully resting on the floor, hips as far back in the chair } \\
\text { as possible, and the hips and knees positioned at } \\
\text { approximately } 90^{\circ}\end{array}$ & Subject seated (same chair for every measurement) \\
\hline Arm position & & Forearms rested on the arms of the chair \\
\hline -Shoulder & Adducted and neutrally rotated & - \\
\hline -Elbow & $\begin{array}{l}\text { Flexed to } 90^{\circ} \text {, the forearm should be in midprone } \\
\text { (neutral) }\end{array}$ & - \\
\hline -Wrist & $\begin{array}{l}\text { Between } 15 \text { and } 30^{\circ} \text { of extension (dorsiflexion) and } \\
0-15^{\circ} \text { of ulnar deviation }\end{array}$ & $\begin{array}{l}\text { Just over the end of the arm of the chair, in a } \\
\text { neutral position, thumb facing upwards }\end{array}$ \\
\hline Trials & Three trials & $\begin{array}{l}\text { Three trials on each side, alternating sides (start with } \\
\text { the right hand) }\end{array}$ \\
\hline \multicolumn{3}{|l|}{ Dynamometer } \\
\hline -Model & Jamar dynamometer & Jamar hydraulic hand dynamometer \\
\hline -Calibration & Yes & - \\
\hline -Handle position & 2nd & $\begin{array}{l}\text { Thumb is round one side of the handle and the four } \\
\text { fingers are around the other side }\end{array}$ \\
\hline Acquisition time & At least $3 \mathrm{~s}$ & - \\
\hline Rest time & At least $15 \mathrm{~s}$ & - \\
\hline Instructions & $\begin{array}{l}\text { "This test will tell me your maximum grip strength. } \\
\text { When I say go, grip as hard as you can until I say } \\
\text { stop. Before each trial, I will ask you 'Are you ready?' } \\
\text { and then tell you 'Go'. Stop immediately if you } \\
\text { experience any unusual pain or discomfort at any } \\
\text { point during testing. Do you have any questions? } \\
\text { Are you ready? Go!". "Harder... harder... harder...Relax" }\end{array}$ & $\begin{array}{l}\text { 'I want you to squeeze as hard as you can for as } \\
\text { long as you can until I say stop. Squeeze, squeeze, } \\
\text { squeeze, stop' (when the needle stops rising) }\end{array}$ \\
\hline HGS analysis & Mean of three trials & Maximal grip score from all six trials \\
\hline
\end{tabular}

sarcopenia and frailty, the major studies that suggested a diagnosis using HGS did not recommend a protocol for its measurement, neither referred to the protocols used to estimate the outlined cut-off points. There is a necessity to include guidelines concerning a standardised protocol in the consensus made by European and International societies. That will allow the results of the studies to be more comparable and more suitable for the application in clinical practice.

In order to describe with precision the handgrip strength protocol used, researchers should always make reference to which protocol was adopted (when applied). For a complete description of the protocol, we suggest that all the points addressed in Table 3 should be mentioned in the methods section of the articles, and therefore include the description of the posture, arm position (including shoulder, elbow and wrist positions), number of trials, characteristics of the dynamometer (brand, model, resolution, calibration and handle position), acquisition and rest time, the applied instructions and the HGS values used in the analysis. The cut-off points to identify low HGS for sarcopenia or frailty should also be stated.
Additionally, deviations to the protocol must be described.

\section{Strengths and limitations}

Some strengths of this systematic review can be highlighted. Besides the original search, we additionally handsearched the references of the included articles for a broader research. Plus, for our knowledge there is no other review of literature that comprises a detailed description of the methods of HGS in observational and experimental studies about sarcopenia and frailty in older adults and that considered the most recent protocols proposed for HGS measurement.

This article also had a few limitations. Data was only searched in two databases (Pubmed and Web of Science) and the inclusion of other databases could increase the range of articles found. In addition, we identified three articles in which we could not locate the references made for the full procedure. The focus of the present revision was to gather information regarding HGS methods, hence, we have not evaluated the methodologic quality of the included studies. In our opinion, we do not consider that the limitations would substantially alter our results. 


\section{Conclusion}

In conclusion, the majority of the studies included did not describe a complete procedure of HGS measurement. The high heterogeneity between the protocols used, in sarcopenia and frailty related studies, create an enormous difficulty in drawing comparative conclusions among them. Even though, there are suggested standardised procedures, present results reinforce the need to uniform the procedure not only in the studies that diagnose these conditions but also in studies which present normative data. Further studies should evaluate which factors contribute to higher HGS values. Meanwhile, we suggest the adoption of the most recent ASHT protocol. In our opinion, this is the most detailed one and, thus, it is less probable to generate differences in HGS values between the studies. Nevertheless, we embrace that the complexity of this protocol may increase the difficulty in its application, especially in clinical practice. Future studies of these issues should include a complete description of the procedure, mentioning the deviations to the protocol.

\section{Abbreviations}

ASHT: American Society of Hand Therapists; CHS: Cardiovascular Health Study; EWGSOP: European Working Group on Sarcopenia in Older People; HGS: Handgrip strength; IWGS: International Working Group on Sarcopenia; PRISMA: Preferred Reporting Items for Systematic Reviews and Meta-Analyses

\section{Acknowledgements}

Not applicable.

\section{Funding}

Not applicable.

\section{Availability of data and materials}

The datasets analysed during the current study available from the corresponding author on reasonable request.

\section{Authors' contributions}

RS and TA conceived of the study, and participated in its design and coordination and helped to draft the manuscript. Both authors read and approved the final version of the manuscript.

Ethics approval and consent to participate

Not applicable.

\section{Consent for publication}

Not applicable.

\section{Competing interests}

The authors declare that they have no competing interests.

\section{Publisher's Note}

Springer Nature remains neutral with regard to jurisdictional claims in published maps and institutional affiliations.

Received: 8 December 2016 Accepted: 8 October 2017 Published online: 16 October 2017

\section{References}

1. WHO. World report on ageing and health. Luxembourg: World Health Organization; 2015.

2. Cruz-Jentoft AJ, Baeyens JP, Bauer JM, Boirie Y, Cederholm T, Landi F, et al. Sarcopenia: European consensus on definition and diagnosis: report of the
European working group on sarcopenia in older people. Age Ageing. 2010; 39(4):412-23.

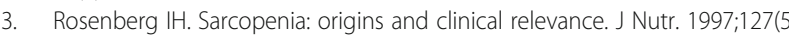
Suppl):990s-1s.

4. Fielding RA, Vellas B, Evans WJ, Bhasin S, Morley JE, Newman AB, et al. Sarcopenia: an undiagnosed condition in older adults. Current consensus definition: prevalence, etiology, and consequences. International working group on sarcopenia. J Am Med Dir Assoc. 2011;12(4):249-56.

5. Xue QL. The frailty syndrome: definition and natural history. Clin Geriatr Med. 2011:27(1):1-15.

6. Woods NF, LaCroix AZ, Gray SL, Aragaki A, Cochrane BB, Brunner RL, et al. Frailty: emergence and consequences in women aged 65 and older in the Women's Health Initiative observational study. J Am Geriatr Soc. 2005;53(8): 1321-30.

7. Ensrud KE, Ewing SK, Taylor BC, Fink HA, Stone KL, Cauley JA, et al. Frailty and risk of falls, fracture, and mortality in older women: the study of osteoporotic fractures. J Gerontol A Biol Sci Med Sci. 2007;62(7):744-51.

8. Cawthon PM, Marshall LM, Michael Y, Dam TT, Ensrud KE, Barrett-Connor E, et al. Frailty in older men: prevalence, progression, and relationship with mortality. J Am Geriatr Soc. 2007;55(8):1216-23.

9. Wong CH, Weiss D, Sourial N, Karunananthan S, Quail JM, Wolfson C, et al. Frailty and its association with disability and comorbidity in a communitydwelling sample of seniors in Montreal: a cross-sectional study. Aging Clin Exp Res. 2010;22(1):54-62.

10. Fried LP, Tangen CM, Walston J, Newman AB, Hirsch C, Gottdiener J, et al. Frailty in older adults: evidence for a phenotype. J Gerontol A Biol Sci Med Sci. 2001:56(3):M146-56.

11. Bouillon K, Kivimaki M, Hamer M, Sabia S, Fransson El, Singh-Manoux A, et al. Measures of frailty in population-based studies: an overview. BMC Geriatr. 2013;13:64

12. Massy-Westropp NM, Gill TK, Taylor AW, Bohannon RW, Hill CL. Hand grip strength: age and gender stratified normative data in a population-based study. BMC Res Notes. 2011;4:127.

13. Rantanen T, Volpato S, Ferrucci L, Heikkinen E, Fried LP, Guralnik JM. Handgrip strength and cause-specific and total mortality in older disabled women: exploring the mechanism. J Am Geriatr Soc. 2003;51(5):636-41.

14. Frederiksen H, Hjelmborg J, Mortensen J, McGue M, Vaupel JW, Christensen K. Age trajectories of grip strength: cross-sectional and longitudinal data among 8,342 Danes aged 46 to 102. Ann Epidemiol. 2006;16(7):554-62.

15. Budziareck MB, Pureza Duarte RR, Barbosa-Silva MC. Reference values and determinants for handgrip strength in healthy subjects. Clin Nutr. 2008; 27(3):357-62.

16. Luna-Heredia E, Martin-Pena G, Ruiz-Galiana J. Handgrip dynamometry in healthy adults. Clin Nutr. 2005;24(2):250-8.

17. Bohannon RW, Schaubert KL. Test-retest reliability of grip-strength measures obtained over a 12-week interval from community-dwelling elders. J Hand Ther. 2005:18(4):426-7.

18. Peolsson A, Hedlund R, Oberg B. Intra- and inter-tester reliability and reference values for hand strength. J Rehabil Med. 2001;33(1):36-41.

19. Flood A, Chung A, Parker H, Kearns V, O'Sullivan TA. The use of hand grip strength as a predictor of nutrition status in hospital patients. Clin Nutr. 2014;33(1):106-14

20. Balogun JA, Akomolafe CT, Amusa LO. Grip strength: effects of testing posture and elbow position. Arch Phys Med Rehabil. 1991;72(5):280-3.

21. O'Driscoll SW, Horii E, Ness R, Cahalan TD, Richards RR, An K-N. The relationship between wrist position, grasp size, and grip strength. J Hand Surg Am. 1992;17(1):169-77.

22. Incel NA, Ceceli E, Durukan PB, Erdem HR, Yorgancioglu ZR. Grip strength: effect of hand dominance. Singapore Med. 2002;43(5):234-7.

23. Firrell JC, Crain GM. Which setting of the dynamometer provides maximal grip strength? J Hand Surg Am. 1996;21(3):397-401.

24. Fess E, Moran C. Clinical assessment recommendations. 1st ed. Indianapolis: American Society of Hand Therapists; 1981.

25. Fess E. Clinical assessment recommendations. Chicago: American Society of Hand Therapists; 1992

26. MacDermid J, Solomon G, Fedorczyk J, Valdes K. Clinical assessment recommendations 3rd edition: Impairment-based conditions. American Society of Hand Therapists; 2015.

27. Roberts HC, Denison HJ, Martin HJ, Patel HP, Syddall H, Cooper C, et al. A review of the measurement of grip strength in clinical and epidemiological studies: towards a standardised approach. Age Ageing. 2011;40(4):423-9. 
28. Moher D, Liberati A, Tetzlaff J, Altman DG. Preferred reporting items for systematic reviews and meta-analyses: the PRISMA statement. PLoS Med. 2009;6(7):e1000097.

29. Fess EE. A method for checking Jamar dynamometer calibration. J Hand Ther. 1987;1(1):28-32.

30. Innes E. Handgrip strength testing: a review of the literature. Aust Occup Ther J. 1999;46(3):120-40.

31. Guerra RS, Amaral TF. Comparison of hand dynamometers in elderly people. J Nutr Health Aging. 2009;13(10):907-12.

32. Amaral JF, Mancini M, Novo Junior JM. Comparison of three hand dynamometers in relation to the accuracy and precision of the measurements. Rev Bras Fisioter. 2012;16(3):216-24.

33. Desrosiers J, Hebert R, Bravo G, Dutil E. Comparison of the Jamar dynamometer and the Martin vigorimeter for grip strength measurements in a healthy elderly population. Scand J Rehabil Med. 1995:27(3):137-43.

34. Mathiowetz V, Vizenor $L$, Melander D. Comparison of baseline instruments to the Jamar dynamometer and the B\&L Engineering Pinch Gauge. OTJR. 2000;20(3):147-62.

35. Reis MM, Arantes PMM. [Medida da força de preensão manual- validade e confiabilidade do dinamômetro saehan.] Fisioter Pesqui. 2011;18:176-81.

36. Bohannon RW. Grip strength: a summary of studies comparing dominant and nondominant limb measurements. Percept Mot Skills. 2003:96(3 Pt 1):728-30.

37. Petersen $\mathrm{P}$, Petrick $\mathrm{M}$, Connor $\mathrm{H}$, Conklin D. Grip strength and hand dominance: challenging the 10\% rule. Am J Occup Ther. 1989;43(7):444-7.

38. Schmidt RT, Toews JV. Grip strength as measured by the Jamar dynamometer. Arch Phys Med Rehabil. 1970;51(6):321-7.

39. El-Sais WM, Mohammad WS. Influence of different testing postures on hand grip strength. Eur Sci J. 2014;10(36):290-301.

40. Watanabe T, Owashi K, Kanauchi Y, Mura N, Takahara M, Ogino T. The shortterm reliability of grip strength measurement and the effects of posture and grip span. J Hand Surg Am. 2005;30(3):603-9.

41. De S, Sengupta P, Maity P, Pal A, Dhara P. Effect of body posture on hand grip strength in adult Bengalee population. JESP. 2011;7(2):79-88.

42. Oxford KL. Elbow positioning for maximum grip performance. J Hand Ther 2000;13(1):33-6.

43. Mathiowetz $V$, Rennells $C$, Donahoe L. Effect of elbow position on grip and key pinch strength. J Hand Surg Am. 1985;10(5):694-7.

44. Su CY, Lin JH, Chien TH, Cheng KF, Sung YT. Grip strength in different positions of elbow and shoulder. Arch Phys Med Rehabil. 1994;75(7):812-5.

45. Parvatikar $V$, Mukkannavar $P$. Comparative study of grip strength in different positions of shoulder and elbow with wrist in neutral and extension positions. JESP. 2009:5(2):67-75

46. Ruiz-Ruiz J, Mesa JLM, Gutiérrez A, Castillo MJ. Hand size influences optimal grip span in women but not in men. J Hand Surg Am. 2002;27(5):897-901.

47. Trampisch US, Franke J, Jedamzik N, Hinrichs T, Platen P. Optimal Jamar dynamometer handle position to assess maximal isometric hand grip strength in epidemiological studies. J Hand Surg Am. 2012;37(11):2368-73.

48. Mathiowetz V, Weber K, Volland G, Kashman N. Reliability and validity of grip and pinch strength evaluations. J Hand Surg Am. 1984;9(2):222-6.

49. Abizanda P, Navarro JL, Garcia-Tomas MI, Lopez-Jimenez E, MartinezSanchez E, Paterna G. Validity and usefulness of hand-held dynamometry for measuring muscle strength in community-dwelling older persons. Arch Gerontol Geriatr. 2012;54(1):21-7.

50. Coldham F, Lewis J, Lee $\mathrm{H}$. The reliability of one vs. three grip trials in symptomatic and asymptomatic subjects. J Hand Ther. 2006;19(3):318-26.

51. Jung MC, Hallbeck MS. The effects of instruction, verbal encouragement, and visual feedback on static handgrip strength. Proc Hum Factors Ergon Soc Annu Meet. 1999;43(12):703-7.

52. Abellan van Kan G, Cesari M, Gillette-Guyonnet S, Dupuy C, Nourhashemi F, Schott AM, et al. Sarcopenia and cognitive impairment in elderly women: results from the EPIDOS cohort. Age Ageing. 2013;42(2):196-202.

53. Akin S, Mucuk S, Ozturk A, Mazicioglu M, Gocer S, Arguvanli S, et al. Muscle function-dependent sarcopenia and cut-off values of possible predictors in community-dwelling Turkish elderly: calf circumference, midarm muscle circumference and walking speed. Eur J Clin Nut. 2015;69(10):1087-90.

54. Alexandre Tda S, Duarte YA, Santos JL, Wong R, Lebrao ML. Prevalence and associated factors of sarcopenia among elderly in Brazil: findings from the SABE study. J Nutr Health Aging. 2014;18(3):284-90.

55. Barichella M, Pinelli G, lorio L, Cassani E, Valentino A, Pusani C, et al. Sarcopenia and Dynapenia in patients with parkinsonism. J Am Med Dir Assoc. 2016;17(7):640-6.
56. Bastiaanse LP, Hilgenkamp TI, Echteld MA, Evenhuis HM. Prevalence and associated factors of sarcopenia in older adults with intellectual disabilities. Res Dev Disabil. 2012;33(6):2004-12.

57. Beaudart C, Reginster JY, Slomian J, Buckinx F, Dardenne N, Quabron A, et al. Estimation of sarcopenia prevalence using various assessment tools. Exp Gerontol. 2015;61:31-7.

58. Beaudart C, Reginster JY, Petermans J, Gillain S, Quabron A, Locquet M, et al. Quality of life and physical components linked to sarcopenia: the SarcoPhAge study. Exp Gerontol. 2015;69:103-10.

59. Bijlsma AY, Meskers CGM, Ling CHY, Narici M, Kurrle SE, Cameron ID, et al. Defining sarcopenia: the impact of different diagnostic criteria on the prevalence of sarcopenia in a large middle aged cohort. Age. 2013;35(3):871-81.

60. Bijlsma AY, Meskers MC, Molendijk M, Westendorp RG, Sipila S, Stenroth L, et al. Diagnostic measures for sarcopenia and bone mineral density. Osteoporos Int. 2013;24(10):2681-91.

61. Campbell TM, Vallis LA. Predicting fat-free mass index and sarcopenia in assisted-living older adults. Age. 2014;36(4):9674

62. Cerri AP, Bellelli G, Mazzone A, Pittella F, Landi F, Zambon A, et al. Sarcopenia and malnutrition in acutely ill hospitalized elderly: prevalence and outcomes. Clin Nutr. 2015;34(4):745-51.

63. Cuesta F, Formiga F, Lopez-Soto A, Masanes F, Ruiz D, Artaza I, et al. Prevalence of sarcopenia in patients attending outpatient geriatric clinics: the ELLI study. Age Ageing. 2015:44(5):807-9.

64. Fukuda DH, Smith-Ryan AE, Kendall KL, Moon JR, Stout JR. Simplified method of clinical phenotyping for older men and women using established field-based measures. Exp Gerontol. 2013;48(12):1479-88.

65. Garatachea N, Fiuza-Luces C, Torres-Luque G, Yvert T, Santiago C, GomezGallego F, et al. Single and combined influence of ACE and ACTN3 genotypes on muscle phenotypes in octogenarians. Eur J Appl Physiol. 2012;112(7):2409-20.

66. Gonzalez-Montalvo Jl, Alarcon T, Gotor P, Queipo R, Velasco R, Hoyos R, et al. Prevalence of sarcopenia in acute hip fracture patients and its influence on short-term clinical outcome. Geriatr Gerontol Int. 2015.

67. Gray M, Glenn JM, Binns A. Predicting sarcopenia from functional measures among community-dwelling older adults. Age. 2016;38(1):22.

68. Han DS, Chang KV, Li CM, Lin YH, Kao TW, Tsai KS, et al. Skeletal muscle mass adjusted by height correlated better with muscular functions than that adjusted by body weight in defining sarcopenia. Sci Rep. 2016;6:19457.

69. Hashemi R, Shafiee G, Motlagh AD, Pasalar P, Esmailzadeh A, Siassi F, et al. Sarcopenia and its associated factors in Iranian older individuals: results of SARIR study. Arch Gerontol Geriatr. 2016;66:18-22.

70. Merkies IS, Schmitz PI, Samijn JP, Meche FG, Toyka KV, van Doorn PA. Assessing grip strength in healthy individuals and patients with immunemediated polyneuropathies. Muscle Nerve. 2000;23(9):1393-401.

71. Kemmler W, Teschler M, Goisser S, Bebenek M, von Stengel S, Bollheimer $L C$, et al. Prevalence of sarcopenia in Germany and the corresponding effect of osteoarthritis in females 70 years and older living in the community: results of the FORMoSA study. Clin Interv Aging. 2015;10:1565-73.

72. Lee WJ, Liu LK, Peng LN, Lin MH, Chen LK. Comparisons of sarcopenia defined by IWGS and EWGSOP criteria among older people: results from the I-Lan longitudinal aging study. J Am Med Dir Assoc. 2013;14(7):528.e1-7.

73. Lee ES, Park HM. Prevalence of sarcopenia in healthy Korean elderly women. J Bone Miner Metab. 2015;22(4):191-5.

74. Maeda K, Akagi J. Sarcopenia is an independent risk factor of dysphagia in hospitalized older people. Geriatr Gerontol Int. 2015;

75. Martinez BP, Batista AK, Gomes IB, Olivieri FM, Camelier FW, Camelier AA. Frequency of sarcopenia and associated factors among hospitalized elderly patients. BMC Musculoskelet Disord. 2015;16:108.

76. McIntosh El, Smale KB, Vallis LA. Predicting fat-free mass index and sarcopenia: a pilot study in community-dwelling older adults. Age. 2013;35(6):2423-34.

77. Mijnarends DM, Koster A, Schols JM, Meijers JM, Halfens RJ, Gudnason V, et al. Physical activity and incidence of sarcopenia: the population-based AGES-Reykjavik study. Age Ageing. 2016;

78. Moon JH, Moon JH, Kim KM, Choi SH, Lim S, Park KS, et al. Sarcopenia as a predictor of future cognitive impairment in older adults. J Nutr Health Aging. 2016;20(5):496-502.

79. Morat T, Gilmore KJ, Rice CL. Neuromuscular function in different stages of sarcopenia. Exp Gerontol. 2016;81:28-36.

80. Pagotto $V$, Silveira EA. Applicability and agreement of different diagnostic criteria for sarcopenia estimation in the elderly. Arch Gerontol Geriatr. 2014; 59(2):288-94. 
81. Patel HP, Syddall HE, Jameson K, Robinson S, Denison H, Roberts HC, et al. Prevalence of sarcopenia in community-dwelling older people in the UK using the European working group on sarcopenia in older people (EWGSOP) definition: findings from the Hertfordshire cohort study (HCS). Age Ageing. 2013;42(3):378-84.

82. Rondanelli M, Guido D, Opizzi A, Faliva MA, Perna S, Grassi MA. Path model of sarcopenia on bone mass loss in elderly subjects. J Nutr Health Aging. 2014;18(1):15-21.

83. Sanchez-Rodriguez D, Marco E, Miralles R, Guillen-Sola A, Vazquez-lbar O, Escalada F, et al. Does gait speed contribute to sarcopenia case-finding in a postacute rehabilitation setting? Arch Gerontol Geriatr. 2015;61(2):176-81.

84. Sjoblom S, Suuronen J, Rikkonen T, Honkanen R, Kroger H, Sirola J. Relationship between postmenopausal osteoporosis and the components of clinical sarcopenia. Maturitas. 2013;75(2):175-80.

85. Sousa AS, Guerra RS, Fonseca I, Pichel F, Amaral TF. Sarcopenia among hospitalized patients - a cross-sectional study. Clin Nutr. 2015;34(6):1239-44

86. Spira D, Norman K, Nikolov J, Demuth I, Steinhagen-Thiessen E, Eckardt R. Prevalence and definition of sarcopenia in community dwelling older people: data from the berlin aging study II (BASE-II). Z Gerontol Geriatr. 2015.

87. Verschueren S, Gielen E, O'Neill TW, Pye SR, Adams JE, Ward KA, et al. Sarcopenia and its relationship with bone mineral density in middle-aged and elderly European men. Osteoporos Int. 2013;24(1):87-98.

88. Vetrano DL, Landi F, Volpato S, Corsonello A, Meloni E, Bernabei R, et al. Association of sarcopenia with short- and long-term mortality in older adults admitted to acute care wards: results from the CRIME study. J Gerontol A Biol Sci Med Sci. 2014;69(9):1154-61.

89. Yalcin A, Aras S, Atmis V, Cengiz OK, Varli M, Cinar E, et al. Sarcopenia prevalence and factors associated with sarcopenia in older people living in a nursing home in Ankara Turkey. Geriatr Gerontol Int. 2015.

90. Yoshida D, Suzuki T, Shimada H, Park H, Makizako H. T, et al. using two different algorithms to determine the prevalence of sarcopenia. Geriatr Gerontol Int. 2014;14:46-51.

91. Yu S, Appleton S, Adams R, Chapman I, Wittert G, Visvanathan T, et al. The impact of low muscle mass definition on the prevalence of sarcopenia in older Australians. Biomed Res Int. 2014;2014:361790.

92. Abizanda P, Lopez MD, Garcia VP, Estrella Jde D, da Silva GA, Vilardell NB, et al. Effects of an oral nutritional supplementation plus physical exercise intervention on the physical function, nutritional status, and quality of life in frail institutionalized older adults: The ACTIVNES Study. J Am Med Dir Assoc. 2015;16(5):439.e9-.e16.

93. Abou-Raya S, Abou-Raya A. Osteoporosis and congestive heart failure (CHF) in the elderly patient: double disease burden. Arch Gerontol Geriatr. 2009; 49(2):250-4.

94. Bandeen-Roche K, Seplaki CL, Huang J, Buta B, Kalyani RR, Varadhan R, et al. Frailty in older adults: a nationally representative profile in the United States. J Gerontol A Biol Sci Med Sci. 2015:70(11):1427-34

95. Buttery AK, Martin FC. Knowledge, attitudes and intentions about participation in physical activity of older post-acute hospital inpatients. Physiotherapy. 2009;95(3):192-8.

96. Bohannon RW, Peolsson A, Massy-Westropp N, Desrosiers J, Bear-Lehman J. Reference values for adult grip strength measured with a Jamar dynamometer: a descriptive meta-analysis. Physiotherapy. 2006;92(1):11-5.

97. Buttery AK, Busch MA, Gaertner B, Scheidt-Nave C, Fuchs J. Prevalence and correlates of frailty among older adults: findings from the German health interview and examination survey. BMC Geriatr. 2015;15.

98. Chang SF, Yang RS, Lin TC, Chiu SC, Chen ML, Lee HC. The discrimination of using the short physical performance battery to screen frailty for community-dwelling elderly people. J Nurs Scholarsh. 2014;46(3):207-15.

99. da Camara SM, Alvarado BE, Guralnik JM, Guerra RO, Maciel AC. Using the short physical performance battery to screen for frailty in youngold adults with distinct socioeconomic conditions. Geriatr Gerontol Int 2013;13(2):421-8.

100. Danilovich MK, Corcos DM, Marquez DX, Eisenstein AR, Hughes SL. Performance measures, hours of caregiving assistance, and risk of adverse care outcomes among older adult users of Medicaid home and community-based services. SAGE Open Med. 2015;3:2050312115614588.

101. Dato S, Montesanto A, Lagani V, Jeune B, Christensen K, Passarino G. Frailty phenotypes in the elderly based on cluster analysis: a longitudinal study of two Danish cohorts. Evidence for a genetic influence on frailty. Age. 2012; 34(3):571-82.
102. Evenhuis HM, Hermans H, Hilgenkamp TIM, Bastiaanse LP, Echteld MA Frailty and disability in older adults with intellectual disabilities: results from the healthy ageing and intellectual disability study. J Am Geriatr Soc. 2012; 60(5):934-8.

103. Gurina NA, Frolova EV, Degryse JMA. A roadmap of aging in Russia: the prevalence of frailty in community-dwelling older adults in the St. Petersburg district - the "crystal" study. J Am Geriatr Soc. 2011;59(6):980-8.

104. Haider S, Luger E, Kapan A, Titze S, Lackinger C, Schindler KE, et al. Associations between daily physical activity, handgrip strength, muscle mass, physical performance and quality of life in prefrail and frail community-dwelling older adults. Qual Life Res. 2016.

105. Hoogendijk EO, Suanet B, Dent E, Deeg DJ, Aartsen MJ. Adverse effects of frailty on social functioning in older adults: results from the longitudinal aging study Amsterdam. Maturitas. 2015.

106. Kang JY, Kim CH, Sung EJ, Shin HC, Shin WJ, Jung KH. The association between frailty and cognition in elderly women. Korean J Fam Med. 2016; 37(3):164-70.

107. Kim S, Park JL, Hwang HS, Kim YP. Correlation between frailty and cognitive function in non-demented community dwelling older Koreans. Korean J Fam Med. 2014;35(6):309-20.

108. Klein $B E$, Klein R, Knudtson MD, Lee KE. Relationship of measures of frailty to visual function: the beaver dam eye study. Trans Am Ophthalmol Soc. 2003; 101:191-9.

109. Kwon J, Yoshida Y, Yoshida H, Kim H, Suzuki T, Lee Y. Effects of a combined physical training and nutrition intervention on physical performance and health-related quality of life in Prefrail older women living in the community: a randomized controlled trial. J Am Med Dir Assoc. 2015;16(3).

110. Lee $Y$, Kim J, Han ES, Ryu M, Cho Y, Chae S. Frailty and body mass index as predictors of 3-year mortality in older adults living in the community. Gerontology. 2014;60(6):475-82.

111. Mohr BA, Bhasin S, Kupelian V, Araujo AB, O'Donnell AB, McKinlay JB. Testosterone, sex hormone-binding globulin, and frailty in older men. J Am Geriatr Soc. 2007:55(4):548-55.

112. Mora M, Granada ML, Palomera E, Serra-Prat M, Puig-Domingo M. Obestatin is associated to muscle strength, functional capacity and cognitive status in old women. Age. 2013;35(6):2515-23.

113. Moreira BD. Dos Anjos DMD, Pereira DS, Sampaio RF, Pereira LSM, Dias RC, et al. the geriatric depression scale and the timed up and go test predict fear of falling in community-dwelling elderly women with type 2 diabetes mellitus: a cross-sectional study. BMC Geriatr. 2016;16.

114. Muller M, van den Beld AW, van der Schouw YT, Grobbee DE, Lamberts SW Effects of dehydroepiandrosterone and atamestane supplementation on frailty in elderly men. J Clin Endocrinol Metab. 2006;91(10):3988-91.

115. Parentoni AN, Lustosa LP, Santos KDd SLF, Ferreira FO, Mendonça VA. [Comparação da força muscular respiratória entre os subgrupos de fragilidade em idosas da comunidade]. Fisioter Pesqui. 2013;20(4):361-6.

116. Passarino G, Montesanto A, De Rango F, Garasto S, Berardelli M, Domma F, et al. A cluster analysis to define human aging phenotypes. Biogerontology. 2007;8(3):283-90.

117. Samper-Ternent R, Al Snih S, Raji MA, Markides KS, Ottenbacher KJ. Relationship between frailty and cognitive decline in older Mexican Americans. J Am Geriatr Soc. 2008;56(10):1845-52.

118. Sanders JL, Singh J, Minster RL, Walston JD, Matteini AM, Christensen K, et al. Association between mortality and heritability of the scale of aging vigor in epidemiology. J Am Geriatr Soc. 2016.

119. Saum KU, Mueller H, Stegmaier C, Hauer K, Raum E, Brenner H. Development and evaluation of a modification of the fried frailty criteria using population-independent Cutpoints. J Am Geriatr Soc. 2012;60(11): 2110-5.

120. Seematter-Bagnoud L, Santos-Eggimann B, Rochat S, Martin E, Karmaniola A, Aminian $\mathrm{K}$, et al. Vulnerability in high-functioning persons aged 65 to 70 years: the importance of the fear factor. Aging Clin Exp Res. 2010;22(3):212-8.

121. Tieland M, Dirks ML, van der Zwaluw N, Verdijk LB, van de Rest O, de Groot LCPGM, et al. Protein supplementation increases muscle mass gain during prolonged resistance-type exercise training in frail elderly people: a randomized, double-blind, placebo-controlled trial. J Am Med Dir Assoc 2012;13(8):713-9.

122. Vieira Al, Nogueira D, de Azevedo Reis E, da Lapa Rosado M, Vania Nunes M, Castro-Caldas A. Hand tactile discrimination, social touch and frailty 
criteria in elderly people: a cross sectional observational study. Arch Gerontol Geriatr. 2016;66:73-81.

123. Walston J, Arking DE, Fallin D, Li T, Beamer B, Xue Q, et al. IL-6 gene variation is not associated with increased serum levels of IL-6, muscle, weakness, or frailty in older women. Exp Gerontol. 2005;40(4):344-52.

124. Wu IC, Shiesh SC, Kuo PH, Lin XZ. High oxidative stress is correlated with frailty in elderly chinese. J Am Geriatr Soc. 2009;57(9):1666-71.

Submit your next manuscript to BioMed Central and we will help you at every step:

- We accept pre-submission inquiries

- Our selector tool helps you to find the most relevant journal

- We provide round the clock customer support

- Convenient online submission

- Thorough peer review

- Inclusion in PubMed and all major indexing services

- Maximum visibility for your research

Submit your manuscript at www.biomedcentral.com/submit 